\title{
Progress of carbon dioxide reforming methane over carbonaceous catalyst to Syngas
}

\author{
Fengbo Guo and Wanli Jia \\ School of Chemical and Environmental engineering, North University of China, Taiyuan, 030051, \\ CHINA \\ agfbo@nuc.edu.cn
}

Keywords: Carbon Dioxide Reforming of Methane; carbonaceous catalyst; Progress; Syngas. Abstract: Carbon dioxide and methane are the main greenhouse gas, $\mathrm{CH}_{4}-\mathrm{CO}_{2}$ reforming can transform the $\mathrm{CO}_{2}$ in the gasification gas and the $\mathrm{CH}_{4}$ in the coke oven gas into the syngas, the ratio of $\mathrm{H}_{2} / \mathrm{CO}$ in syngas can be adjusted by the ratio of gasification gas and coke oven gas according to the requirement, also the syngas can be the raw material of the Fischer-Tropsch synthesis, which make up for the steam reforming shortage of relatively high hydrogen over carbon, at the same time, full utilization of $\mathrm{CH}_{4}$ in the coke oven gas and $\mathrm{CO}_{2}$ emission reduction are realized, so as to achieve the goal of resources conservation and environment protection.

\section{Introduction}

The $\mathrm{CH}_{4}$ molecules have high symmetry and stability, and the electron transfer of the $\mathrm{CO}_{2}$ have needed the energy of up to $20.4 \mathrm{eV}$, which similarly have strong self-stability. The $\mathrm{CH}_{4}-\mathrm{CO}_{2}$ reforming is one of the most challenging projects in catalysis and energy research areas. The high-temperature reactivity and selectivity of the $\mathrm{CH}_{4}-\mathrm{CO}_{2}$ reforming limited by the thermodynamic are needed to be solved by developing efficient catalyst. Science Fischer [1] studied on the $\mathrm{CH}_{4}-\mathrm{CO}_{2}$ reforming to syngas, it attracts lots of researchers' attention, Currently, studies on the catalysts used in $\mathrm{CH}_{4}-\mathrm{CO}_{2}$ reforming mainly focused on the noble metals and transition metals used. According to the current research status, the statements in this paper mainly focus on the factors which impact catalyst activity and stability, and discussed the future research priorities.

\section{The catalysts of $\mathrm{CH}_{4}-\mathrm{CO}_{2}$ reforming}

The active components. $\mathrm{CH}_{4}-\mathrm{CO}_{2}$ reforming is a strong endothermic reaction, which needs to be carried out under high temperature conditions, in order to reduce the activation energy; the reforming is mainly under the catalytic conditions. Studies [2-4] have shown that the transition metal of VIII group $\mathrm{Ni}, \mathrm{Co}, \mathrm{Ru}, \mathrm{Rh}, \mathrm{Rd}$, Ir, etc. have a very good activity on the $\mathrm{CH}_{4}-\mathrm{CO}_{2}$ reforming, the noble metal catalyst has characteristics of high activity and resistance to carbon deposition, of which the performance of $\mathrm{Rh}, \mathrm{Ru}$, Ir catalyst are the best, $\mathrm{Pd}$, $\mathrm{Pt}$ is slightly inferior, but the resource is scarcity and expensive, non-noble metal catalysts quickly lost the activity due to carbon deposition, the deactivation order is $\mathrm{Ni}>\mathrm{Co}>\mathrm{Cu}>\mathrm{Fe}$. According to the defects of the single metal active component, researchers carried out the study of double-metal and multi-metal active component, Tao Huang [5] used Ni-Mo as the active component, found that the Ni-Mo catalysts has strong alkalinity and more uniform distribution, $\mathrm{MO}_{2} \mathrm{C}$ can interact with metal supports, So it is concluded that the Mo is the 
main reason of refusing the carbon deposition, especially the carbon deposition with shell-like. In summary, the non-noble metal catalysts nickel and cobalt are better, so they becoming the focus of the study.

The carriers. The firmness of catalyst loading, catalyst life, factors affecting the catalyst activity must be considered when selecting the catalyst carrier, the catalyst used in $\mathrm{CH}_{4}-\mathrm{CO}_{2}$ reforming reaction is the supported metal catalyst, so the surface acidity and basicity of carrier and the interaction between the catalysts have a significant impact on catalyst activity, so the catalytic activity, selectivity and stability vary with the carrier. JH Bitter [2] comparative studied the effect of carrier $\gamma-\mathrm{Al}_{2} \mathrm{O}_{3}, \mathrm{TiO}_{2}$ and $\mathrm{ZrO}_{2}$ over Pt catalysts on the reaction, the results show that the catalytic activity related to the carrier and its microstructure, the catalysts stability order is: $\mathrm{Pt} / \mathrm{ZrO}_{2}>$ $\mathrm{Pt} / \mathrm{TiO}_{2}>\mathrm{Pt} / \gamma-\mathrm{Al}_{2} \mathrm{O}_{3}$; Eli Ruckensteinl [6] found that $\mathrm{NiO} / \mathrm{MgO}$ catalyst after reduction has the best performance, and the activity and stability of the $\mathrm{NiO} / \mathrm{CaO}$ and the $\mathrm{NiO} / \mathrm{SrO}$ are poor.

The promoter. Promoter is a small substance has no activity or little activity itself, which means it does not have the catalytic ability, but it can achieve the purpose of improving the catalyst activity, selectivity, stability, and anti-toxicity by having physical or chemical interaction. The promoter commonly used in $\mathrm{CH}_{4}-\mathrm{CO}_{2}$ reforming are rare earth metal(CeOError! Reference source not

found.), alkali metal $\mathrm{K}_{2} \mathrm{O}, \mathrm{CaO}$ ) oxides of alkaline earth metal ( $\mathrm{La}_{2} \mathrm{O}_{3}$ Error! Reference source not found.) and so on.

$\mathrm{Li}$ Wenze [7] found that adding of $\mathrm{CeO}_{2}$ additives can effectively improve Ni-based catalyst of the specific surface area, catalytic activity and resistance to carbon deposition, etc., $\mathrm{CeO}_{2}$ particles dispersed on the carrier surface of $\mathrm{Al}_{2} \mathrm{O}_{3}$, and interaction between $\mathrm{CeO}_{2}$ and $\mathrm{Ni}$ can improve the dispersion of Ni grains. SM [8] found that adding the promoter lanthanum and cerium in $\mathrm{Pt} / \mathrm{ZrO}_{2}$ can improve the stability of the catalyst and the $\mathrm{CO}_{2}$ absorption, eliminate the carbon deposition produced by $\mathrm{CH}_{4}$ decomposition, at $800^{\circ} \mathrm{C}$, the catalyst has constant specific surface area. Supaporn [9] adding $\mathrm{ZrO}_{2}$ promoter into $\mathrm{Ni} / \mathrm{Al}_{2} \mathrm{O}_{3}$ catalysts, the results show that the adding of $\mathrm{ZrO}_{2}$ strengthen the $\mathrm{CO}_{2}$ broken down to intermediate products around the $\mathrm{ZrO}_{2}$ and $\mathrm{Ni}$, making the carbon deposition gasified and reducing deactivation of active component.

The preparation method of catalyst. The existent form of the catalyst active component is the main factor affecting the catalytic properties, and different preparation methods can make the active component in a different existent form, at present, the preparation methods of the supported catalyst are: sol - gel method, hydrothermal synthesis method, wet impregnation method, excessive dipping, and coprecipitation-load method.

Li Xiancai [10] compared studied the catalyst prepared by the sol-gel method and impregnation method, the results indicate that the catalysts prepared by the sol-gel method had larger specific surface area, showing higher catalytic activities and exhibiting perfect desorption and reduction performances.

Li Ning [11] using co-precipitation method, citric acid complex method, hydrothermal synthesis and impregnation precipitation method prepared the $\mathrm{NiO}-\mathrm{ZrO}_{2}-\mathrm{Al}_{2} \mathrm{O}_{3}$ catalyst, found that the crystal structure is different due to the different preparation methods, the $\mathrm{NiO}$ grains is smaller prepared by citric acid complex method, the small grain of $\mathrm{NiO}$ strongly interact with the carrier.

Deactivation of catalyst. At the initial stage of $\mathrm{CH}_{4}-\mathrm{CO}_{2}$ reforming, the catalyst generally has good activity, but with the whole reaction carried through, the catalytic activity gradually reduced or even completely inactivated, the reasons for this phenomenon are the carbon deposition on catalyst surface 
and sintering of metal catalysts, $\mathrm{CH}_{4}-\mathrm{CO}_{2}$ reforming process is a very complex reaction system, the main reaction resulting in carbon deposition are:

$\mathrm{CO}$ disproportion : $\quad 2 \mathrm{CO} \rightarrow \mathrm{CO}_{2}+\mathrm{C} \Delta \mathrm{H}_{298 \mathrm{~K}}=-172 \mathrm{~kJ} / \mathrm{mol}$

$\mathrm{CH}_{4}$ decomposition : $\mathrm{CH}_{4} \rightarrow \mathrm{C}+2 \mathrm{H}_{2} \quad \Delta \mathrm{H}_{298 \mathrm{~K}}=75 \mathrm{~kJ} / \mathrm{mol}$

Tatsuro Horiuchi [12] found that adding the oxides of alkaline earth metal oxide in the catalysts can inhibit carbon deposition formation, which mainly due to the alkaline oxides can react with $\mathrm{CO}_{2}$ occurs, resulting in the formation of a rich electron density on catalyst surface, helping to eliminate the carbon deposition. Toshihiko Osaki [13] proved the sulfide in the catalyst can inhibit the formation of carbon deposition. Liu Haitao [14] used XRD, XPS, TEM, elemental analysis and activity evaluation to study the effect of transition metal oxides of $\mathrm{MoO}_{3}$ and $\mathrm{WO}_{3}$ on characteristics of $\mathrm{Ni}-\mathrm{SiO}_{2}$ catalyst and $\mathrm{CH}_{4}-\mathrm{CO}_{2}$ reforming, found that the adding of the transition metal oxides improved the extra nuclear electron density of $\mathrm{Ni}$, enhanced resistance to carbon deposition, also improved the dispersion of the active component, the relative oxygen concentration increased, the ability of anti-sintering $\mathrm{Ni}-\mathrm{SiO}_{2}$ and anti-carbon deposition increased.

\section{The kinetics of $\mathrm{CH}_{4}-\mathrm{CO}_{2}$ reforming}

The kinetics is to study the effect of various physical and chemical factors (such as temperature, pressure, concentration, the media in the reaction, catalysts, flow and temperature distribution, residence time distribution, etc.) on the reaction rate and the corresponding reaction mechanism and mathematical expressions, etc. To study the kinetics of $\mathrm{CH}_{4}-\mathrm{CO}_{2}$ reforming has significance on methane conversion and utilization.

A. Nandini [15] studied the $\mathrm{CH}_{4}-\mathrm{CO}_{2}$ reforming over catalyst of $\mathrm{Ni}-\mathrm{K} / \mathrm{CeO}_{2}-\mathrm{Al}_{2} \mathrm{O}_{3}$, compared to the activation energy of $\mathrm{CH}_{4}, \mathrm{CO}_{2}, \mathrm{H}_{2}, \mathrm{CO}$, it can be obtained the activation energy of $\mathrm{CH}_{4}$ almost equals to the $\mathrm{CO}_{2}$ 's activation energy, due to the energy-interaction, the activation energy of $\mathrm{H}_{2}$ is higher than the CO's, the proposed reaction rate equation is:

$$
r_{C H_{4}}=\frac{k_{1 L} p_{C_{4}}}{\left[\left(k_{1 L} p_{C H_{4}} p_{C O} / k_{7 L} K_{a} p_{C O_{2}}\right)+\left(K_{b} p_{C_{2}} p_{H_{2}}^{\frac{1}{2}} / p_{C O}\right)+\left(k_{1 L} p_{C H_{4}} / k_{7 L}\right)+1\right]}
$$

Sun Zhiqiang [16] examined coal and $\mathrm{CO}_{2}$ gasification during co-conversion of coal and $\mathrm{CH}_{4}$, a kinetic reaction model was established:

$$
\frac{d x}{d t}=k_{0} e^{\left(-\frac{E a}{R T}\right)} p_{C_{4}}^{m} p_{C O_{2}}^{n}(1-x)^{\delta}
$$

Using the obtained model, the activation energy of coal is $3124 \mathrm{~kJ} / \mathrm{mol}$, the reaction order of $\mathrm{CO}_{2}$ is 0.3 , and the reaction order of $\mathrm{CH}_{4}$ is -0.13 . in the co-transformation system, the activation energy of the carbon the activation energy of carbon is greater than that of $\mathrm{CO}_{2}$ gasification, $\mathrm{CO}_{2}$ gasification reaction is more difficult to carry out, where $\mathrm{m}$ is negative, indicating that the increasing methane partial pressure increased the carbon number, while $\mathrm{n}$ is positive, indicating that the $\mathrm{CO}_{2}$ partial pressure in reaction gas can accelerate the rate of carbon gasification. The results showed that, when $\delta$ equals to 1 , the kinetic model is very close to the experimental structure. 
Ji Min [17] studied the $\mathrm{CH}_{4}-\mathrm{CO}_{2}$ reforming over the $\mathrm{Sr}(\mathrm{La}) \mathrm{NiAl}_{11} \mathrm{O}_{19}$ catalyst, obtained the kinetic equation of carbon deposition:

$$
\mathrm{v}=\frac{\mathrm{dW}}{\mathrm{dt}}=\mathrm{Ae}^{-\frac{\mathrm{E}}{\mathrm{RT}}} \mathrm{P}_{\mathrm{CH}_{4}}^{\mathrm{a}} \mathrm{P}_{\mathrm{CO}_{2}}^{\mathrm{b}}
$$

By mapping can be got, $\mathrm{a}=1, \mathrm{~b}=-0.5$. The rate of carbon deposition increased with increasing $\mathrm{CH}_{4}$ partial pressure, decreased with increasing $\mathrm{CO}_{2}$ partial pressure, thereby increasing the ratio of $\mathrm{CO}_{2} / \mathrm{CH}_{4}$ can improve the ability to resistance to the carbon deposition.

\section{The application of carbonaceous material in the $\mathrm{CH}_{4}-\mathrm{CO}_{2}$ reforming}

Carbonaceous material used as the catalyst for the $\mathrm{CH}_{4}-\mathrm{CO}_{2}$ reforming is getting more and more researchers' attention, and lots of study have been done, at present, the main carbonaceous catalysts are activated carbon, carbon black and coal char [18-21].

JL Pinilla [22] studied the $\mathrm{CH}_{4}-\mathrm{CO}_{2}$ reforming over nanostructured carbonaceous material catalyst, the results show that the methane conversion increased with increasing temperature, the carbon dioxide conversion is very high at the initial stage, and then decreased with increasing temperature,

when the temperature exceeds $800^{\circ} \mathrm{C}$, the main ingredient in the product gas are $\mathrm{H}_{2}$ and $\mathrm{CO}$ and tends

to balance, when the temperature below $800^{\circ} \mathrm{C}$, the content of $\mathrm{H}_{2}$ in product gas bigger than the $\mathrm{CO}$,

in the equilibrium state, $\mathrm{H}_{2} / \mathrm{CO}>1$. The higher the $\mathrm{CH}_{4}: \mathrm{CO}_{2}$ ratio is, the higher the $\mathrm{CH}_{4}$ conversion, while the $\mathrm{CO}_{2}$ is opposite, in the product gas, the ratio of $\mathrm{H}_{2} / \mathrm{CO}$ depends largely on temperature and feed gas ratio, the higher the temperature is, the lower the $\mathrm{H}_{2} / \mathrm{CO}$ ratio is, and the $\mathrm{H}_{2} / \mathrm{CO}$ ratio has the proportional relationship with reaction gas ratio.

Li Yanbing $[23,24]$ studied the effect of coal chars obtained by coking the Tongchuan coal, Yingzi coal, Xuzhou coal and Liuqiao coal on $\mathrm{CH}_{4}-\mathrm{CO}_{2}$ reforming, found that the catalytic activity vary from different coal char, the order of methane conversion rates were: Tongchuan coal char>Xuzhou coal char>Liuqiao coal char>Maoyingzi coal char, indicating that the coal char with higher specific surface area and lower ash content has higher catalytic activity; Mohammad Haghighi et al [25] using the coal char made by bituminous coal as a catalyst to study the thermodynamics of $\mathrm{CH}_{4}-\mathrm{CO}_{2}$ reforming, examined the components variation of $\mathrm{CH}_{4}, \mathrm{CO}_{2}, \mathrm{H}_{2}, \mathrm{CO}, \mathrm{H} 2 \mathrm{O}, \mathrm{C}, \mathrm{C}_{2} \mathrm{H}_{2}, \mathrm{C}_{2} \mathrm{H}_{4}, \mathrm{C}_{2} \mathrm{H}_{6}$, found that when the temperature rises from $700 \mathrm{~K}$ to $1000 \mathrm{~K}$, the mole ratio of $\mathrm{CO}$ and $\mathrm{H}_{2}$ in product gas increased, at $1073-1223 \mathrm{~K}$, the main product of the $\mathrm{CH}_{4}-\mathrm{CO}_{2}$ reforming are $\mathrm{CO}, \mathrm{H}_{2}$, when the temperature up to $1100 \mathrm{~K}$, the selectivity of $\mathrm{CO}$ and $\mathrm{H}_{2}$ almost up to $100 \%$.

Zhang Huawei [26] studied the effect of Datong semi-coke on the steam and carbon dioxide reforming reactions of methane, and found that the semi-coke can lower the initial decomposition temperature of methane, and the conversion improved significantly, the mass of the semi-coke almost no change before and after the reforming reaction by the material balance calculation of the $\mathrm{H}$ atom and $\mathrm{C}$ atom, the semi-coke play the role of "catalyst" on the reforming reaction; Yin Xingliang [27] load the Co catalyst on the Datong semi-coke, to study the impact of preparation methods on reforming reaction, and the results show that the catalyst prepared by wetness impregnation method have higher activity, the catalyst prepared by wetness impregnation method then treated by ultrasonic was significantly higher than the catalyst just prepared by prepared by wetness impregnation method , the reason mainly is the catalyst treated by ultrasonic is conducive to uniform distribution of the active substance on the catalyst carrier surface, increasing the catalyst active sites. This paper indicates that basic oxide $\left(\mathrm{K}_{2} \mathrm{O}, \mathrm{Na}_{2} \mathrm{O}, \mathrm{CaO}\right)$ in the carrier can absorb carbon dioxide, and it improve 
the ability to resistance to carbon deposition, making the catalyst maintain the stability for a longer time.

Yongfa Zhang [28] and Fengbo Guo [29,30] studied the $\mathrm{CH}_{4}-\mathrm{CO}_{2}$ reforming over carbonaceous material catalyst under pressure in a small self-made high pressure reactor, found that the initial conversion of $\mathrm{CH}_{4}$ and $\mathrm{CO}_{2}$ is relatively high, then decreased and stabilized, the greater the pressure is, the reaction gas conversion rate lower is. By examine the IR spectroscopy of carbonaceous material catalyst before and after reaction, found that the $\mathrm{C}-\mathrm{O}$ structure in the carbonaceous material catalyst is the component of the active center in the $\mathrm{CH}_{4}-\mathrm{CO}_{2}$ reforming. the specific surface area and pore volume of carbonaceous material catalyst are reduced by BET characterization of the semi-coke before and after reaction under pressure, mainly due to the carbon deposition generated during the reaction deposited on the catalyst surface and porous, which making the specific surface area and pore volume of carbonaceous material catalyst decreased, so the catalytic activity decreased.

\section{Conclusions}

Although researchers have done a lot of research about the $\mathrm{CH}_{4}-\mathrm{CO}_{2}$ reforming to syngas, the catalyst deactivation is still a problem, which limiting the $\mathrm{CH}_{4}-\mathrm{CO}_{2}$ reforming to syngas industrialization, so the future work should be focused on developing high activity, high selectivity, metal catalysts with good stability and other new carbonaceous material catalyst, also reveal the mechanism of reforming reaction and learn the rule of the catalyst deactivation. Furthermore, the researches under other forms of energy supply (plasma, microwave, ultrasonic wave and solar energy, etc.) Should be conducted, providing a new way for catalytic $\mathrm{CH}_{4}-\mathrm{CO}_{2}$ reforming.

\section{Acknowledgements}

This work was financially supported by the Shanxi Provincial Natural Science Foundation (2014011014-7).

\section{References}

[1] F. Fischer and H. Tropsch: Brennst-Chem (1923), p. 276

[2] J.H. Bitter, W. Hally and K. Seshan: Catal. Today Vol. 29 (1996), p. 349

[3] S.B.Wang and G.Q. Lu: Energy Fuel (1996), p. 896

[4] L. Xu, H. Song and L. Chou: Appl. Catal. B: Environ. Vol. 177-190 (2011), p. 108

[5] T. Huang, W. Huang and J. Huang: Fuel Process. Technol. Vol. 92 (2011), p. 1868

[6] Eli. Ruckenstein and Y. Hu: Appl. Catal. A: Gen. Vol. 133 (1995), p. 149

[7] W. Li, R.Yang and W. Gao: J. Shenyang University of Technology Vol. 30 (2008), p. 237

[8] S.M. Stagg and D.E. Resasco: Studies in Surface Science and Catalysis Vol. 119 (1998), p. 813

[9] T. Supaporn, S. Chairut and T. Apichai: Fuel Process. Technol. Vol. 89 (2008), p. 160

[10] X. LI , Q. Hu and Y. Yang: J. Rare Earths Vol. 26 (2008), p. 864

[11] N. Li , J. Chen and X. Jiang: Speciality Petrochemicals Vol. 27 (2011), p. 34

[12] H. Tatsuro, S. Kaori, F. Takehisa, K. Yukio, O.Toshihiko and M. Toshiaki: Appl. Catal. A: Gen. Vol. 144 (1996), p.111

[13] T. Osaki, T. Horiuchi and K. Suzuki: Appl. Catal. A: Gen. Vol. 155 (1997), p. 229

[14] H. Liu, H. Tian and X. Wang: J. Molecular Catalysis Vol. 21 (2007), p. 304

[15] A. Nandini, K.K. Pant and S.C. Dhingra: Catalyst Vol. 308 (2006), p. 119

[16] Z. Sun, J. Wu and Y. Wang: J. Fuel Chemistry and Technology Vol. 37 (2009), p. 410

[17] M. Ji, Z. Wu and Bi Yingl: J. Molecular Catalysis Vol. 12 (1998), p. 355 
[18] G. Zhang, Y. Dong and M. Feng : J. Chemical Engineering Vol. 156 (2010), p. 519

[19] M. Khoshtinat Nikoo and N.A.S. Amin. Fuel Process. Technol. Vol. 92 (2011), p. 678

[20] F. Guo, Y. Zhang, G. Zhang and H. Zhao: J. Power Sources 23 Vol. (2013)1, p. 82

[21] F. Guo, S. Sh, Y. Zhang and H. Zhao: energy fuel Vol. (2014), p. 6511

[22] J.L. Pinilla, S. de Llobet and I. Suelves: carbonaceous material Vol. 90 (2011), p. 2245

[23] Y. Li, R. Xiao and B. Jin: J. Combustion Science and Technology Vol. 15 (2009), p. 238

[34] Y. Li, R. Xiao and B. Jin: Chemical Engineering and Technology Vol. 30 (2008), p. 91

[25] H. Mohammad, Z. Sun and J. Wu: P. Combust. Inst. Vol. 31 (2007), p. 1983

[26] H. Zhang, W. Zhao and Y. Zhang: Coal Conversion Vol. 28 (2005), p. 40

[27] X. Yin: Taiyuan University of Technology (2011)

[28] Y. Zhang, G. Zhang, B. Zhang and F. Guo: J. Chemical Engineering Vol. 173 (2011), p. 593

[29] F. Guo, Y. Zhang, H. Zhao and G. Zhang: Res. J. Chem. Environ. Vol. 16 (2012), p. 14

[30] F. Guo and Y. Zhang: Asian J. Chem. Vol. 24 (2012), p. 787 